University of Tulsa College of Law

TU Law Digital Commons

Articles, Chapters in Books and Other Contributions to Scholarly Works

2014

\title{
Curing the Disobedient Patient: Medication Adherence Programs as Pharmaceutical Marketing Tools
}

\author{
Matt Lamkin \\ University of Tulsa College of Law \\ Carl Elliott
}

Follow this and additional works at: http://digitalcommons.law.utulsa.edu/fac_pub

Part of the Health Law Commons

The article originally appeared in the Journal of Law, Medicine and Ethics. The definitive version is available at www.blackwell-synergy.com

\section{Recommended Citation}

Lamkin, Matt and Elliott, Carl, "Curing the Disobedient Patient: Medication Adherence Programs as Pharmaceutical Marketing Tools" (2014). Articles, Chapters in Books and Other Contributions to Scholarly Works. Paper 475.

http://digitalcommons.law.utulsa.edu/fac_pub/475

This Article is brought to you for free and open access by TU Law Digital Commons. It has been accepted for inclusion in Articles, Chapters in Books and Other Contributions to Scholarly Works by an authorized administrator of TU Law Digital Commons. For more information, please contact daniel-bell@utulsa.edu. 
Curing the Disobedient Patient: Medication Adherence Programs as Pharmaceutical Marketing Tools

\author{
Matt Lamkin and Carl Elliott
}

A bout a week after Maran Wolston was preAscribed Copaxone, a drug for multiple sclero1 sis (MS), she got a phone call from a nurse at an organization called Shared Solutions. The organization was familiar to Wolston; when her neurologist had asked permission to share her health information with Shared Solutions, Wolston had agreed, assuming it was connected to her health insurance.

The nurse who called Wolston was checking in to see how the treatment was going. It was not going well. While Copaxone is not typically associated with some of the unpleasant side effects of other MS drugs, it does have at least one serious drawback: the drug must be injected every day. The injections can be brutally painful. "No matter where I injected the drug each day, the injection site swelled up into a huge welt and felt like a gigantic bee sting," Wolston writes. "I don't ordinarily use a cane to walk, but every time I injected Copaxone somewhere in my legs, I needed a cane just to move around my house."'

The Shared Solutions nurse gave Wolston some suggestions about adjusting her injection technique. She also asked if Wolston would be interested in talking to a fellow patient who could share her experiences with Copaxone and answer Wolston's questions about living with MS. Wolston agreed. A few days later, she got a call from an elderly woman who had been taking Copaxone for several years. The woman heaped praise on Copaxone and emphasized the importance of taking the drug religiously. Soon the woman was calling so frequently that Wolston began to get curious.

It did not take her long to discover that Shared Solutions is an arm of Teva Neuroscience, the pharmaceutical company that sells Copaxone. The Shared Solutions nurse was a Teva employee whose job was to keep Wolston taking Copaxone, as was the elderly patient "peer" who called. Even Wolston's neurologist, who prescribed her Copaxone, was in Teva's employ. He had taken more than $\$ 70,000$ from the drug-maker in the previous two years, in the form of speaker fees, honoraria, and "promotional/marketing and consulting" fees for Teva. This may explain why none of these people ever suggested that she discontinue treatment or change to another drug. Wolston writes, "Maybe I'm old-fashioned, but as a patient I felt that the party who should have been helping was my neurology clinic, not a division of a pharmaceutical company."

For a long time, drug companies have marketed their drugs primarily by persuading doctors to write

Matt Lamkin, J.D., is an Assistant Professor at the University of Tulsa College of Law in Tulsa, OK. Carl Elliott, M.D., Ph.D., is a Professor at the University of Minnesota Center for Bioethics. 
more prescriptions - either by sending armies of drug reps into clinics and hospitals, or by saturating the airwaves with ads imploring people to request drugs by their brand names. The strategy has worked well. But there is a drag on profits: many people do not take the drugs they have been prescribed. Increasingly drug companies are trying to remedy that shortcoming through programs that increase patient "adherence" with their prescriptions. These efforts, like Shared Solutions, offer emotional support and technical expertise from people patients trust, including health care professionals like nurses and pharmacists. From what different meanings." Compliance is simply following a treatment regimen as prescribed - taking the correct dose at the right time of day. Adherence, however, is continuing to follow the treatment instructions over the correct period of time - whether it is two weeks, a year, or indefinitely. ${ }^{3}$ Whether this represents a genuinely significant difference or mere rebranding matters little to the underlying imperative behind adherence, which IMS Health defines as the "extent to which a patient follows medical instructions."

Whatever term is used, it should be acknowledged that failure to follow medical instructions can damage patients' health, especially when the patients have a chronic illness for which there is a proven therapy. Today nearly half of all Americans suffer from a chronic illness of some sort, such as diabetes and heart disease, and nearly three quarters of U.S. health care expenditures are spent caring for these individuals. ${ }^{4}$ Many of these illnesses can be managed effectively if patients stick closely to drug regimens prescribed by their doctors. Yet many patients fail to do that. In a 2003 report on patient adherence to prescription medications, the World Health Organization estimated that only about half of patients suffering from chronic illnesses take their medications as pre-

the patients' perspective these interactions can look like medical care. But these programs are being run out of drug companies' marketing departments. The "support" these programs offer is all geared toward one goal: getting patients to get their prescriptions filled and refilled, preferably in perpetuity.

\section{Justifying Adherence}

Efforts to get independent-minded patients to follow their doctors' instructions are nothing new. Until recently the problem was known as "non-compliance," a phrase that took hold in the late 1950s. During the 1980 s and 1990s, however, the notion of "non-compliance" took a beating from social scientists and bioethicists, who complained that it reinforced a paternalistic, authoritarian model of the doctor-patient relationship. ${ }^{2}$ By the early 2000 s, the word "compliance" had started to sound anachronistic enough to warrant replacement by a new word: "adherence."

The word "adherence" has been embraced by the pharmaceutical industry, which is often careful to distinguish adherence from compliance in its promotional materials. In a document on adherence to specialty products, for instance, IMS Health claims that adherence and compliance have "precise and some- scribed. ${ }^{5}$ This can result in acute complications. By one estimate, mortality rates for "non-adherent" patients with heart disease or diabetes are nearly double the rates for "adherent" patients. ${ }^{6}$

Non-adherence can also be costly. In fact, it has become customary for any writer who argues for the importance of adherence strategies to emphasize the enormous costs of non-adherence, generally in the first paragraph of the article. "Approximately $30 \%$ to $50 \%$ of US adults are not adherent to long-term medications leading to an estimated $\$ 100$ billion in preventable [hospital admissions] costs annually," according to a recent article in $J A M A .{ }^{7}$ The New England Healthcare Institute (NEHI) puts the figure even higher. It estimates patient non-adherence is responsible for as much as $\$ 290$ billion in avoidable medical spending each year, or approximately $13 \%$ of total U.S. health care expenditures. ${ }^{8}$

Of course, it is probably no coincidence that NEHI's members include Merck, AstraZeneca, GlaxoSmithKline, and many other drug companies. Non-adherence represents a serious financial blow to the pharmaceutical industry too - as much as $\$ 564$ billion a year in revenue losses, if you believe Capgemini Consulting. ${ }^{9}$ No doubt this is why pharmaceutical compa- 
nies have begun to hire "dedicated patient adherence teams" and drug marketers are sponsoring annual "patient adherence and advocacy" conferences. From 2009 to 2012, American pharmaceutical companies increased their budget allocations for patient adherence by $281 \% .^{10}$

In pharma's telling, these efforts are simply a way of doing well by doing good. Since increasing adherence with prescription medications is supposed to improve patient health, increasing drug sales can be packaged as a form of public service. Armed with the logic that more drug consumption yields healthier people, pharmaceutical marketers glide easily from "better patient outcomes" to "better brand performance." In a press release, McKesson Corporation explained that its success in boosting sales proved that "pharmaceuti- caps, which fit on standard pharmaceutical bottles, are equipped with microchips and transmitters that send information to the internet via wireless routers. ${ }^{14}$ Patients, caregivers, or pharmacists can program the caps, entering the proper times for the medications to be taken. When that time arrives, a light on the cap blinks. If the patient fails to open the bottle within a few minutes, the cap prompts the patient by playing a ring tone. If the patient still has not opened the bottle within an hour, Vitality follows up with an automated phone call. Vitality also knows when a prescription is (or should be) empty, and automatically orders a refill from the pharmacy.

Investing in a comprehensive adherence program pays off best for expensive specialty drugs. As the president of one company that runs adherence programs

\section{People do not trust drug companies. When Harris Interactive conducted} a poll asking respondents, "Which of these industries do you think are generally honest and trustworthy - so that you normally believe a statement by a company in that industry," only $12 \%$ placed the pharmaceutical industry in that category. As a result, drug makers are now trying to deliver their marketing messages through trusted intermediaries - including nurses, pharmacists, and even fellow patients.

cal manufacturers can effectively drive brand performance and patient loyalty through improvement of patient health outcomes." 11

The logic of this approach - where drug adherence, brand loyalty, and patient health all merge into a seamless whole - can be seen clearly in "Your Way," Pfizer's adherence program for Toviaz, a treatment for overactive bladder. Pfizer conducted clinical trials to establish the efficacy not only of the drug, but of the Your Way adherence program. The company suggested that if it could show that the program got patients to take Toviaz more consistently, then the company could report that fact on the drug's label. ${ }^{12}$ The more effective the marketing, the reasoning goes, the more effective the drug.

Not all adherence problems require elaborate adherence programs. In cases where non-adherence comes from patients forgetting to take their medication, for example, the solution can be relatively straightforward. A well-known example is the Dialpak, a circular blister pack first introduced in 1963 to help women remember to take a birth control pill every day. ${ }^{13}$ GlowCaps, pill bottle tops sold by Vitality, Inc., take this concept several steps further. These put it, "Candidly, the higher the price of the drug the more likely that somebody is going to do this. You're not going to be doing this for Tums." 15 Many of these programs encourage adherence to drugs that patients really hate to take. For example, MS patients who take Rebif (interferon beta 1a) can suffer flu-like symptoms such as nausea, vomiting, and stomach pain after each of their three weekly injections. They can escape those side effects by choosing Copaxone, but only if they are willing to inject themselves daily and endure occasional welts, hives, and other unpleasant reactions.

To get people to take an enormously expensive drug that produces painful side effects and may offer few beneficial effects - and to do so every day, for the rest of their lives - requires changing people's "beliefs, intentions, and values." ${ }^{16}$ Drug companies have learned that DTC advertising cannot do that. Adherence programs for these drugs require repeated, personal interactions with people whom patients trust. People do not trust drug companies. When Harris Interactive conducted a poll asking respondents, "Which of these industries do you think are generally honest and trustworthy so that you normally believe a statement by a company in that industry," only $12 \%$ placed the pharmaceutical 
industry in that category. ${ }^{17}$ As a result, drug makers are now trying to deliver their marketing messages through trusted intermediaries - including nurses, pharmacists, and even fellow patients.

\section{Nurses and Patients as Drug Reps}

In the old days, to the extent drug companies paid attention to adherence at all, they did so using demographic data. For example, they relied on research indicating older patients are more likely to struggle with managing several different medications, while younger patients are more likely to be deterred by outof-pocket costs. But there are limits to this approach, since reasons for non-adherence vary on an individual basis and, at least according to one marketer, are "correlated with patients' perceptions, beliefs, and attitudes toward taking their medications rather than their age or income."18 So for drugs that are profitable enough to justify the expense, drug companies are turning to nurses, pharmacists, and "patient ambassadors" to tailor and deliver "frequent, personalized interactions" with patients in order to promote adherence. ${ }^{19}$

Most makers of expensive specialty drugs have established drug-specific call centers staffed by nurses, including the makers of MS drugs, such as Shared Solutions for Copaxone, MS Lifelines for Rebif, and ActiveSource for Tysabri. Patients who have been prescribed one of these drugs can call and ask questions about how to use the drug or manage its side effects. Unlike the medical professionals who are being paid by patients' insurers, however, who limit their time consulting with patients because of low reimbursement rates, these nurses are willing to spend time with patients and offer emotional support. And unlike ordinary nurses or doctors, pharma's nurses can be reached 24 hours a day, 7 days a week. They also make outgoing calls to check up on patients and help them work through any challenges they might be having in sticking with the drug.

The reason this strategy works is simple: nurses are the most trusted professionals in America. ${ }^{20}$ That, together with their medical training and experience dealing with patients, makes them ideal candidates to counsel patients about sticking with their drugs. "Nurses can quickly build a rapport with patients and establish trust, allowing them to elicit information and assess potential non-adherence risks," a drug marketing executive explains. "Patients are therefore more likely to accept the information provided at face value and are better able to integrate the information when they make decisions regarding taking their medication and follow-up appointments with their prescriber."21

Since these call centers offer trained health care professionals delivering medical advice, patients could be pardoned for believing they are receiving medical care - a service whose fundamental purpose is to promote their health. In fact, the companies running these programs actively encourage that belief. McKesson Specialty Pharmaceutical's Kerr Holbrook described his company's nurse support line as "an extension of the physician's office."22 But the real purpose is to ensure that customers stay loyal to the brand - as evidenced by the fact that Mr. Holbrook was a vice president in McKesson's marketing division. According to an online posting seeking nurses to staff the Rebif call center, for example, the nurse's "main objective is to achieve customer satisfaction and ensure customer retention." United BioSource Corporation (UBC), a pharmaceutical support company, touts its ability to leverage patients' trust in its nurses to "provide personal, patient-centric care that inspires brand loyalty."23

When nurses become part of the pharmaceutical marketing machinery, they abdicate their ability to speak frankly with patients regarding their own medical judgments. Unlike nurses whose job is to protect patient health, who are free to discuss off-label uses and offer their own opinions, drug company nurses are restricted in what they can say by FDA rules governing drug promotion. Moreover, by virtue of their employment, their duty to patients is rendered secondary to the goal of customer retention. For example, faced with a patient who has bad reactions to Rebif, a nurse whose main objective is to retain customers may be more likely to suggest ways to lessen or cope with the side effects - even when a nurse concerned only with patient care might advise the patient to talk with her doctor about changing her medication.

Like nurses, pharmacists have become "a key cog in not only the pharmaceutical chain, but also in the marketing of prescription drugs and services." ${ }^{24}$ Pharmacists are effective at improving adherence because patients trust them, ranking pharmacists second only to nurses in terms of professional ethics and honesty. ${ }^{25}$ In addition, patients interact more with pharmacists than any other health care professional. ${ }^{26}$ So pharmacists have many opportunities to influence patients and identify the reasons individual patients are not taking their medications. As pharmaceutical distributor McKesson says, pharmacists can offer "personalized messaging, program enrollment, behavioral coaching and other clinical services at the point of dispensing." 27

McKesson provides these opportunities through its Pharmacy Intervention Program, which uses behavioral psychologists to train pharmacists in "motivational interviewing" - "a proven technique used to uncover and help patients overcome adherence bar- 
riers." ${ }^{28}$ According to McKesson, pharmacists can be trained to listen for "key words and phrases that signal that patients are accepting the adherence messages" and then to help patients build a plan of action, presumably one that will keep them on their medication. ${ }^{29}$ Noting that "non-adherence is not only detrimental to patient health, but also to the health of your brand," McKesson boasts a strong return on investment for drug companies who use this service - as measured by increased drug consumption. ${ }^{30}$

Even patients are playing an increasingly important role in pharmaceutical marketing. For example, the pharmaceutical marketing firm Snow \& Associates offers a program called Patient Ambassadors, which identifies and trains patients to serve as spokespeople for pharmaceutical brands. CEO Brenda Snow explains that enlisting patients in marketing efforts can address "the trust gap that currently exists between pharmaceutical companies and their patient consumers," lending "instant authenticity and credibility" to an industry that sorely needs them..$^{31}$ As Snow points out, even the best doctors may not give patients the sense that they really understand what having a chronic disease is like. "Connecting people with others who have trodden a similar path is enormously important." 32

Not every patient makes a suitable ambassador for a brand. As Snow says, they must be patients whose "authentic stories align with the company's marketing strategies." ${ }^{33}$ This begins with careful selection of patients, who are screened "according to brand specifications." ${ }^{34}$ Once patients are selected, Snow works closely with the Patient Ambassadors to tailor their messages to align with the "brand strategy" of a pharmaceutical industry client. In this way, the company does not need to manipulate what patients say; it merely needs to pick the right patients, who are telling the right stories.

A key function of Patient Ambassadors is to keep patients on a particular therapy for as long as possible. As with nurse and pharmacist marketing programs, ambassadors do this by seeking to change how patients define success and think about harmful side effects. A key role of patient peers, Snow urges, is to provide other patients with strategies to "manage" those side effects, so that patients "are more likely to approach the side effects as hurdles instead of discontinuing use in frustration." ${ }^{35}$ At the same time, communication from carefully selected patients "fosters belief in a successful treatment outcome." The basic idea is to put forward real patients who are happy with the drug to communicate the message that however unpleasant the therapy may be, patients need to endure it to reach the successful treatment outcome.

\section{The Problem with Adherence}

On the surface, improving patient adherence is all gain and no pain. When people are more consistent in taking drugs that are safe and highly effective in treating serious conditions, patients improve their health and drug companies increase their profits, all while saving the health care system money. This scenario has proven attractive not only to drug companies but to policymakers. Congress has authorized employer-sponsored wellness programs to penalize non-adherent employees with thousands of dollars in increased premiums and deductibles. ${ }^{36}$ Last year, $J A M A$ published an article proposing that failure to follow doctors' recommendations should itself be considered a medical condition. The authors argued that doctors should "treat" this medical condition by "target[ing] interventions to the participant's adherence barriers." ${ }^{37}$

But as the $J A M A$ authors noted, those "barriers" include things like "the patient has concluded the benefits of taking medications do not outweigh the costs" and "the patient does not perceive medication to have therapeutic efficacy." Indeed, the most common reason patients do not take their medication is simply because they do not want to - usually because they do not believe they need the medication or do not like the side effects. ${ }^{38}$ Recasting objections to taking medications as "barriers to adherence" that need to be overcome with monetary penalties and behavioral interventions ignores the fact that sometimes patients have good reasons to decline their doctors' advice.

\section{Ineffective and Dangerous}

First, many common medical practices are based on extremely limited evidence, and when they are subjected to rigorous research, they are often reversed..$^{39}$ Practices such as aggressive treatment of diabetes or using statins for primary prevention have been shown to pose serious risks without producing benefits. ${ }^{40} \mathrm{~A}$ 2010 study from the Archives of Internal Medicine found that $58 \%$ of the drugs prescribed to elderly patients could be discontinued and that these patients' quality of life would improve as a result. ${ }^{41}$ An analysis published in $J A M A$ by John Ioannidis showed that one-third of the efficacy claims made in highly-cited journal articles published between 1990 and 2003 were either contradicted by subsequent clinical studies or found to have weaker effects than claimed in the initial articles. ${ }^{42}$ And these numbers reflect only the fraction of trials that researchers tried to replicate. Many trials are never even challenged..$^{43}$

Second, the very companies urging patients to "adhere" to their medications may be hiding serious risks. A prime example is GlaxoSmithKline (GSK)'s 
diabetes drug, Avandia. Although GSK had discovered that Avandia was linked to increased risk of cardiovascular disease as early as 1999 , the company hid that finding for 11 years while promoting the drug heavily. In one internal email, a GSK executive wrote that "[p]er Sr. Mgmt request, these data should not see the light of day to anyone outside of GSK." ${ }^{44}$ It was not until 2007 that the New England Journal of Medicine published an independent meta-analysis indicating Avandia increased patients' risk of death from cardiovascular causes by $64 \% .{ }^{45}$ According to a subsequent independent study, between 1999 and 2009 Avandia was responsible for 47,000 needless heart attacks, strokes, heart failures, or deaths. ${ }^{46}$ In 2010 European regulators pulled the drug off the market, and the FDA placed severe restrictions on its availability.

\section{Adherence Strategies and Antipsychotics}

A similar issue has played out for the entire class of drugs known as atypical antipsychotics. Non-adherence with antipsychotics has been a problem since the 1950 s, when these drugs were introduced for schizophrenia. Although it was clear that antipsychotics could reduce acute psychotic symptoms such as hallucinations, delusions, and disordered thinking, they could also cause serious long-term side effects. The most troubling of these side effects are "extrapyramidal" symptoms such as muscle dystonia, akathisia, and tardive dyskinesia, which can be permanent. Many patients also simply find antipsychotics very unpleasant to take on a daily basis. They say the drugs make them feel sluggish, emotionally dead and zombie-like. ${ }^{47}$ Many patients with schizophrenia will take antipsychotics only until their immediate psychotic symptoms disappear, at which point the unpleasantness of taking the drugs starts to outweigh the apparent benefits.

Over the years, health care workers have attempted a broad array of tactics to persuade patients to stay on their antipsychotics. Some are simple, such as text message reminders or calendars. Others, such as compliance therapy or cognitive-behavioral therapy, depend on "behavioral modification." British researchers have had some success with a more direct approach: they simply gave mentally ill patients money in exchange for taking their medication. ${ }^{48}$ Perhaps the most novel adherence strategy has come from a team funded by Eli Lilly, the manufacturer of the antipsychotic Zyprexa, which has developed a "computer-animated humanoid agent" that simulates face-to-face conversation with patients suffering from schizophrenia. ${ }^{49}$ A typical encounter begins with the humanoid agent walking onto the patient's computer screen, greeting the patient, and conducting a "social and empathic chat," with questions such as, "Have you taken your evening Prolixin yet today?"

While it is true that patients with schizophrenia do not always make good decisions about their medications, especially when they are acutely psychotic, it is also important to acknowledge that there is legitimate controversy as to what the appropriate long-term treatment for schizophrenia is. ${ }^{50}$ In the 2000 s, antipsychotics became the most profitable class of drugs in America, largely because of the claim that the newer, atypical (or "second-generation") antipsychotics such as Zyprexa, Seroquel, and Risperdal carried a minimal risk of causing extrapyramidal side effects. That claim has proven to be largely untrue. In fact, the independent, federally funded CATIE study found not only that the atypical antipsychotics were no more effective than an older generic drug, but that the risk of extrapyramidal side effects was generally just as high. ${ }^{51}$

Enforcing adherence with the atypical antipsychotics has also exposed patients to a whole range of hidden metabolic risks - namely diabetes, hyperglycemia, and weight gain. The major manufacturers of the atypical antipsychotics have all been forced to pay record-breaking penalties for fraud, in part for hiding these risks. Lilly paid a record-setting $\$ 1.4$ billion in federal penalties for fraudulent marketing of Zyprexa in 2009; four years later, Johnson and Johnson paid $\$ 2.2$ billion to settle accusations that it had illegally marketed Risperdal. In 2010, AstraZeneca was forced to pay more than half a billion dollars in 2010 to settle federal investigations into illegal marketing of Seroquel. The company allegedly paid kickbacks to doctors as part of an effort to market the drug off-label for conditions ranging from dementia to ADHD to posttraumatic stress disorder. ${ }^{52}$

\section{Individualized Risk-Benefit Calculus}

Third, deciding whether to take a medication often depends on a highly individual risk-benefit calculus. Most medications involve trade-offs between disease symptoms and drug side effects, between longevity and quality of life, between comfort in the present and potential long-term health gains. A decision not to take a particular medication may simply be a rational, informed decision based on personal experience and values.

Consider Copaxone. As previously discussed, patients taking the drug have to inject themselves with hypodermic needles every day, and patient Maran Wolston noted that these injections can cause painful welts. Some patients experience "immediate postinjection reactions," which they describe as similar to the feeling of a heart attack or severe panic attack. These side effects may seem like reasonable sacri- 
fices in exchange for slowing the progression of MS. But it is far from clear how many patients experience that benefit. In the most favorable studies of Copaxone's efficacy - the ones published by Teva $-34 \%$ of patients taking Copaxone remained relapse-free during the two-year study. ${ }^{53}$ So did $27 \%$ of the patients on placebo. An evaluation by the Cochrane Collaboration, a not-for-profit group that offers independent analysis of drug efficacy, concluded that Copaxone was not effective in treating the progressive form of MS, and had "few beneficial effects" in patients with the relapse-remitting form of the disease. ${ }^{54}$ their drugs treat. The tactic of third-party messaging - inserting your marketing message in the mouth of a credible third party - is a time-honored public relations technique dating back to the time of PR pioneer Edward Bernays. ${ }^{55}$

If adherence programs are different, it is mainly because they take this technique away from the realm of pure communication and move it directly into the business of patient care. Even if companies are technically "transparent" in disclosing their sponsorship of these efforts, their effectiveness relies on blurring the lines between drug promotion and medical care.

What is puzzling is how these adherence programs have largely escaped critical scrutiny. Over the past 15 years, the reputation of pharmaceutical companies has taken a public beating - partly because of litigation, and partly because of sustained academic criticism. It has become clear that pharmaceutical companies have buried unfavorable research data, manipulated clinical trials, paid kickbacks to physicians, bullied academic critics, and ghostwritten journal articles (and in at least one case, an entire fake medical journal). The old claim that pharmaceutical companies' aim is to promote patients' health now seems laughably quaint. Yet pharmaceutical adherence programs are flourishing.

From a systemic perspective, the difference between $27 \%$ and $34 \%$ may be strong evidence in favor of the benefits of increasing Copaxone adherence among patients, since fewer patients experiencing relapses might save the health care system money. But from the patient's perspective, the choice is far less clear. Patients, not the health care system, must endure the side effects and reduced quality of life that goes along with these drugs. And while the system can benefit from small changes in the number of patients experiencing relapses, the odds of any individual patient experiencing benefits from these drugs may be low.

\section{Conclusion}

Part of what distinguishes pharmaceutical adherence programs from garden-variety direct-to-consumer advertising is the way the marketing message is laundered through trusted authorities. In a way, this is nothing new to the pharmaceutical industry. For decades, drug companies have hired academic physicians to deliver marketing talks disguised as medical education; they have employed medical ghostwriters to produce promotional material disguised as journal articles; and they have used celebrities to promote "disease awareness" campaigns for the conditions
When patients get medical advice from medical professionals, they naturally assume that the advice is aimed first at promoting their health, rather than promoting "brand loyalty."

If there is a single reason these adherence programs have worked so well, without any real backlash, it is the premise that boosting adherence benefits patients. If patients are supposed to be taking their medication, then anything that helps them stay on the drugs can be presented as inherently good. From a traditional informed consent perspective, a choice not to take a medication might be thought of as the patient exercising his autonomy. These days, that choice is called a "barrier to adherence" - even if the choice is informed and reasonable. And what might otherwise be seen as unjustified manipulation or deception gets a pass because it is in done in the name of improving health and saving lives.

Of course, pharmaceutical adherence programs are not geared toward promoting patient health, but toward ensuring patients keep using a particular drug. As market research consultants Frost \& Sullivan have acknowledged, "The most compelling reason to invest in these tailored communications is to increase return on investment (ROI) by keeping patients on 
the therapy longer." ${ }^{96}$ McKesson Patient Relationship Solutions assures pharmaceutical companies that the company's "adherence tactics" will "optimize the performance of your brand." 57 And like other intensive marketing strategies, pharmaceutical adherence programs are generally implemented only for new, expensive, on-patent drugs. This is important to keep in mind when hearing arguments about how boosting adherence will save money for the health care system. Preventing a stroke can save a lot of money, but it saves more money to prevent a stroke with an effective generic than an on-patent drug.

What is puzzling is how these adherence programs have largely escaped critical scrutiny. Over the past 15 years, the reputation of pharmaceutical companies has taken a public beating - partly because of litigation, and partly because of sustained academic criticism. It has become clear that pharmaceutical companies have buried unfavorable research data, manipulated clinical trials, paid kickbacks to physicians, bullied academic critics, and ghostwritten journal articles (and in at least one case, an entire fake medical journal). ${ }^{58}$ The old claim that pharmaceutical companies' aim is to promote patients' health now seems laughably quaint. Yet pharmaceutical adherence programs are flourishing.

The success of these programs is symptomatic of the larger ills plaguing our health care system. Thanks in part to the pharmaceutical industry's relentless push toward overtreatment and expensive, on-patent medications, drug companies are the only entities with the resources to give patients this kind of intensive, personalized support. For patients, receiving this kind of attention from drug companies may be preferable to not receiving it at all. Likewise, time-pressed health care professionals and cash-strapped patient support groups may be grateful for the assistance. Indeed, the National Multiple Sclerosis Society ended its own patient support program "because the drug companies were doing such a thorough job." ${ }^{\circ 9}$ And to policymakers desperate to reduce health care costs, the promise of adherence programs - to promote health without cutting services - may be too attractive to resist.

But as with most devil's bargains, the price is likely to be steep. Medical professionals have built a vast reservoir of public trust by acting as fiduciaries with duties to protect patient health. Building that kind of trust is a long and arduous process. Squandering it is quick and easy. All it will take is for patients to discover that the people they have entrusted with their care are salesmen in lab coats. And when even fellow patients are part of pharma's marketing team, patients will be left with nowhere to turn for independent medical advice.
References

1. M. Wolston, "An MS Patient Loses Trust When She Finds Out Her Doctor Is Paid by Drug Companies," Health Affairs 30, no. 12 (2011): 2449-2452.

2 See, e.g., P. Conrad, "The Meaning of Medications: Another Look at Compliance," Social Science and Medicine 20, no. 1 (1985); S. Holm, "What Is Wrong with Compliance?" Journal of Medical Ethics 19, no. 2 (1993): 108-110.

3. "Understanding and Improving Adherence for Specialty Products," IMS Health, available at <http://www.imshealth.com/ deployedfiles/ims/Global/Content/Solutions/Healthcare\%20 Analytics\%20and \%20Services/Specialty\%20Analytics/Understanding_Improving_Adherence_Specialty_Products.pdf> (last visited November 19, 2014).

4. T. Rundall et al., "As Good as It Gets? Chronic Care Management in Nine Leading U.S. Physician Organizations," $B M . J$ 325 (2002): 958-961; G. Anderson and J. Knickman, "Changing the Chronic Care System to Meet People's Needs," Health Affairs 20, no. 6 (2001): 146-160.

5. "Adherence to Long-Term Therapies: Evidence for Action," World Health Organization, 2003, available at $<\mathrm{http}$ //apps. who.int/medicinedocs/en/d/Js4883e/> (last visited November 19, 2014)

6. P. M. Ho, D. J. Magid, F. A. Masoudi, D. L. McClure, and J. S. Rumsfeld, "Adherence to Cardioprotective Medications and Mortality among Patients with Diabetes and Ischemic Heart Disease," BMC Cardiovascular Disorders 6 (2006): 48.

7. Z. A. Marcum, M. Sevick, and S. M. Handler, "Medication Nonadherence: A Diagnosable and Treatable Medical Condition," JAMA 309, no. 20 (2013): 2105-2106.

8. New England Health Institute, "Thinking Outside the Pillbox: A System-Wide Approach to Improving Patient Medication Adherence for Chronic Disease," August 2009.

9. Capgemini Consulting \& HealthPrize Technologies, "Annual Pharmaceutical Revenue Loss Due to Medication Non-Adherence," available at <https://www.adherence564.com/> (last visited November 19, 2014).

10. S. Baum, "Pharma Patient Adherence Budgets Have Increased 281 Percent in Four Years," MedCity News, October 12, 2012, available at $<\mathrm{http}: / /$ medcitynews.com/2012/10/pharmapatient-adherence-budgets-have-increased-281-percent-infour-years/\#ixzz2t7sGEyYr> (last visited November 19, 2014).

11. McKesson Medication Adherence Programs Achieve New Levels of Patient Adoption and Loyalty, Press Release, June 3, 2010, available at <http://www.mckesson.com/about-mckesson/ newsroom/press-releases/2010/mckesson-medication-adherence-programs-achieve-new-levels-of-patient-adoption-andloyalty/> (last visited November 19, 2014).

12. M. Arnold, "Thinking Past the Pill," Medical Marketing $\xi^{\circ}$ Media, October 2010, available at $<\mathrm{http}$ //www.mmm-online. $\mathrm{com} /$ patient-marketing-report-thinking-past-the-pill/article/180045/> (last visited November 19, 2014).

13. D. Rose, "The Reason Why: Smart Packaging Can Improve Habits and Transform Healthcare," Healthspottr, Issue 5, November 19, 2009.

14. Id.

15. A. Pollack, "Take Your Pills, All Your Pills," New York Times, March 11, 2006.

16. Frost \& Sullivan Whitepaper, Patient Nonadherence: Tools for Combating Persistence and Compliance Issues, avaitable at <http://www.frost.com/prod/servlet/cpo/115071625. pdf $\% \mathrm{C} 3 \% \mathrm{BD}>$ (last visited November 19, 2014).

17. Harris Interactive, "Oil, Pharmaceutical, Health Insurance, Tobacco, Banking and Utilities Top the List of Industries That People Would Like to See More Regulated," December 18, 2012, available at <http://www.harrisinteractive.com/NewsRoom/HarrisPolls/tabid/447/mid/1508/articleId/1131/ctl/ ReadCustom\%20Default/Default.aspx $>$ (last visited November 19, 2014).

18. B. Bertha, "The Artful Science of Medication Adherence," PM360, June 2010. 
19. Id.

20. Gallup, "Honesty/Ethics in Professions," December 2013, available at $<\mathrm{http}$ //www.gallup.com/poll/1654/honesty-ethics-professions.aspx $>$ (last visited November 19, 2014)

21. J. Allen and C. Bell, "Nurses: They're Not Just in Hospitals Anymore," PharmaPhorum, November 27, 2013, available at <http://www.pharmaphorum.com/articles/nurses-theyre-notjust-in-hospitals-anymore (last visited November 19, 2014).

22. See Pollack, supra note 15.

23. UBC, "Nursing and Adherence," available at $<\mathrm{http}$ ://www.ubc. com/services/loyalty/nursing-adherence > (last visited November 19, 2014).

24. Ad Age Insights White Paper, Pharmaceutical Marketing, October 17, 2011, available at <http://adage.com/images/bin/ pdf/WPpharmmarketing_revise.pdf> (last visited November 19, 2014).

25. See Gallup Honesty/Ethics in Professions Poll, supra note 20.

26. See Ad Age Insights White Paper, supra note 24.

27. McKesson Patient Relationship Solutions, "Sponsored Clinical Services," available at <http://mprsannounce.mckesson.com/ MPRS/microsite/sponsored clinical_services.htm> (last visited November 19, 2014).

28. McKesson Patient Relationship Solutions, "Pharmacy Intervention Program," available at <http://mprsannounce.mckesson.com/MPRS/microsite/pharmacy_intervention_program. htm> (last visited November 19, 2014).

29. B. Bertha, "The Artful Science of Medication Adherence," PM360, June 2010

30. McKesson Patient Relationship Solutions, available at $<\mathrm{http}: / /$ mprsannounce.mckesson.com/MPRS/microsite/welcome. htm> (last visited November 19, 2014); McKesson Patient Relationship Solutions, "The Future of Medication Adherence," March 2012.

31. B. Snow, "Magnifying the Authentic Voice of the Patient, DTC Perspectives," March 2010, available at <http://www.dtcperspectives.com/wp-content/uploads/2011/02/PatientAmbassadors.pdf > (last visited November 19, 2014).

32. B. Snow, "Make Contact," Pharmaceutical Marketing Europe, January/February 2010.

33. B. Snow, "Magnifying the Authentic Voice of the Patient," DTC Perspectives, March 2010, available at <http://www.dtcperspectives.com/wp-content/uploads/2011/02/PatientAmbassadors.pdf $>$ (last visited November 19, 2014).

34. Snow \& Associates job posting for Advocacy and Recruitment Associate, available at <http://intranet.snow-companies.com/ share/jobposting/0000873> (last visited November 19, 2014).

35. Snow \& Associates, When Executed Effectively and Consistent with FDA Guidelines, Patient Testimonials Continue to Be a Powerful Vehicle for Communicating with Health Consumers Snow: Best Practices 2010, available at <http://snow-companies.com/page/sites/default/files/(5)\%20Snow_Regulatory_ Position_03_10.pdf> (last visited November 19, 2014).

36. M. Lamkin, "Health Care Reform, Wellness Programs \& the Erosion of Informed Consent," Kentucky Law Journal 101 (2013): 435 .

37. Z. A. Marcum, M. Sevick, and S. M. Handler, "Medication Nonadherence: A Diagnosable and Treatable Medical Condition," JAMA 309, no. 20 (2013): 2105-2106.

38. Boston Consulting Group, The Hidden Epidemic: Finding a Cure for Unfilled Prescriptions and Missed Doses (2003), available at <http://www.bcg.com/documents/file14265.pdf> (last visited November 19, 2014).

39. J. P. A. Ioannidis, "Contradicted and Initially Stronger Effects in Highly Cited Clinical Research," JAMA 294, no. 2 (2005): $218-228$, at 224 .
40. D. Giugliano and K. Esposito, "Clinical Inertia as a Clinical Safeguard," JAMA 305 (2011): 1591-1592.

41. D. Garfinkel and D. Mangin, "Feasibility Study of a Systematic Approach for Discontinuation of Multiple Medications in Older Adults: Addressing Polypharmacy," Archives of Internal Medicine 170, no. 18 (2010): 1648-1654.

42. See Ioannidis, supra note 39 , at 223.

43. Id.

44. G. Harris, "Diabetes Drug Maker Hid Test Data, Files Indicate," New York Times, July 13, 2010, at A1.

45. S. E. Nissen and K. Wolski, "Effect of Rosiglitazone on the Risk of Myocardial Infarction and Death from Cardiovascular Causes," New England Journal of Medicine 356, no. 24 (2007): $2457-2471$.

46. G. Harris, "F.D.A. to Restrict Avandia, Citing Heart Risk," Nere York Times, September 23, 2010, at A1.

47. J. Moncrie, D. Cohen, and J. P. Mason, "The Subjective Experience of Taking Antipsychotic Medication: A Content Analysis of Internet Data," Acta Psychiatrica Scandinavica 120, no. 2 (2009): 102-111.

48. S. Priebe and A. Burton, et al., "Financial Incentives to Improve Adherence to Anti-psychotic Maintenance Medication in Nonadherent Patients: A Cluster Randomised Controlled Trial (FIAT)," BMC Psychiatry 9 (2009), available at $<\mathrm{http}$ :/ www. biomedcentral.com/1471-24.4X/9/61> (last visited November 19, 2014).

49. See <http://relationalagents.com/publications/CHIO8-mentalhealth.pdf> (last visited November 19, 2014). Also T. Bickmoreand K. Puskar et al., "Maintaining Reality: Relational Agents for Antipsychotic Medication Adherence," Interacting with Computers 22, no. 4 (2010): 276-288.

50. R. Whitaker, Anatomy of an Epidemic: Magic Bullets, Psychiatric Drugs, and the Astonishing Rise of Mental Illness in America, Broadway Books, 2011.

51. J. A. Lieberman et al., "Effectiveness of Antipsychotic Drugs in Patients with Chronic Schizophrenia," New England Journal of Medicine 353, no. 12 (2005): 1209-1223.

52. H. Khan and P. Thomas, "Drug Giant AstraZeneca to Pay $\$ 520$ Million to Settle Fraud Case," ABC News, April 27, 2010, avaitable at <http://abcnews.go.com/Politics/Health/astrazenecapay-520-million-illegally-marketing-seroquel-schizophrenia/ story? $\mathrm{id}=10488647>$ (last visited November 19, 2014).

53. Copaxone Prescribing Information, available at <http:// copaxone.com/pdfs/PrescribingInformation.aspx> (last visited November 19, 2014).

54. L. La Mantia, L. M. Munari, and R. Lovati, "Glatiramer Acetate for Multiple Sclerosis (Review)," The Cochrane Library 5 (2010), available at <http://www.bibliotecacochrane.com/pdf/ CD004678.pdf $>$ (last visited November 19, 2014).

55. C. Elliott, White Coat, Black Hat: Adventures on the Dark Side of Medicine (Boston: Beacon Press, 2010.)

56. Frost \& Sullivan, The Evolution of Patient Adherence Programs: Moving from Mass Market Relationships to a Personal Approach, available at <https://www.frost.com/prod/servlet/ cpo/115071626.pdf> (last visited November 19, 2014).

57. McKesson Patient Relationship Solutions, The Future of Medication Adherence, March 2012.

58. B. Grant, "Merck Produced Fake Journal," The Scientist, April 30, 2009, available at $<\mathrm{http} / /$ www.the-scientist.com/?articles. view/articleNo/27376/title/Merck-published-fake-journal/> (last visited November 19, 2014).

59. See Pollack, supra note 15. 